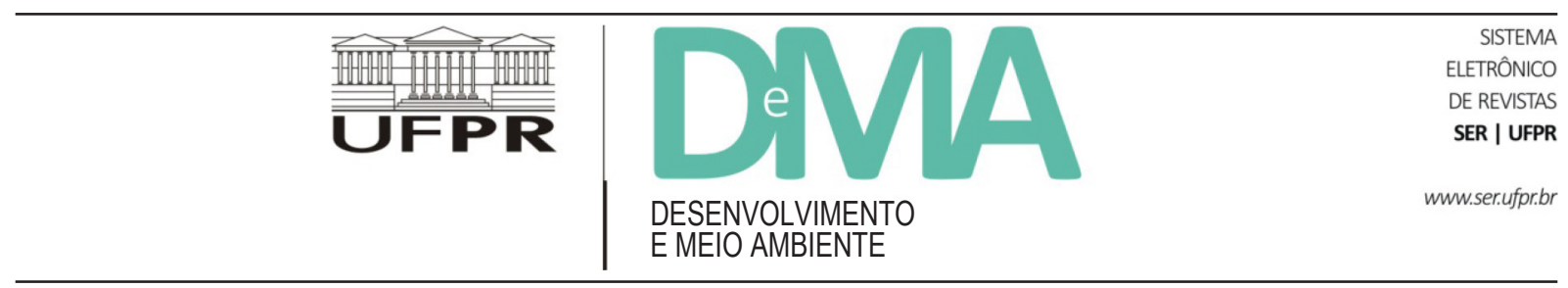

\title{
A administração pública se sustenta?
}

\section{Does public administration sustain itself?}

Bliacheris, Marcos Weiss; Ferreira, Maria Augusta Soares de Oliveira (Org.). Sustentabilidade na Administração Pública: valores e práticas da gestão socioambiental. Belo Horizonte: Fórum, 2012. 312 p. ISBN 978-85-7700-565-9.

\author{
Marcelo Albuquerque LIMA ${ }^{1 *}$ \\ ${ }^{1}$ Programa de Pós-Graduação em Arquitetura e Urbanismo, Universidade de Brasília (UnB), Brasília, DF, Brasil. \\ *E-mail de contato: marceloal71@gmail.com
}

Resenha recebida em 2 de dezembro de 2014, versão final aceita em 24 de julho de 2015.

Os organizadores são advogados da União e coautores de livros e artigos na área de licitações públicas sustentáveis e direito ambiental. Escreveram também obras sobre temas ligados à concessão florestal, à responsabilidade social na administração pública, à mudança climática e aos resíduos sólidos.

Esta coletânea tem como tema principal a sustentabilidade na administração pública, analisada pelos diversos autores sob um prisma jurídico e administrativo. Dividido em duas partes, a primeira trata dos eixos temáticos do programa Agenda Ambiental na Administração Pública (A3P), e a segunda relata experiências práticas de gestão socioambiental em diversas áreas, como educação, engenharia e controle. A organização desta resenha sintetiza assuntos correlatos ao tema principal, que tangenciam as partes e capítulos da obra, a saber: gestão socioambiental; legislação, normatização e licitações sustentáveis; programas e educação ambiental; racionalização de recursos.
Os temas supracitados são comuns em discussões recentes e constantes na administração pública. Suas bases advêm dos primeiros conceitos de sustentabilidade e de mudanças de paradigmas ocorridas nos governos federais desde a década de 1990. Essas mudanças incorporaram a filosofia da eficiência administrativa e a conscientização dos servidores públicos sobre seu papel perante a sociedade como disseminadores de boas práticas e de proteção ao meio ambiente.

A gestão socioambiental na administração pública envolve aspectos de legislação e governança. Os autores mencionam as vantagens desse tipo de gestão, como a redução do desperdício, eficiência da produção, redução do impacto ambiental e dos custos, aumento da competitividade dos produtos e geração de lucro e de visibilidade para as empresas. Afirmam também que são consequências evidentes a atração de trabalhadores de maior qualidade, $\mathrm{o}$ aumento da satisfação no trabalho e maior produtividade, bem como maior fidelidade dos consumidores. 
No caso da administração pública, os autores afirmam que o foco das ações socioambientais está nos processos internos, regidos por normas constitucionais e legais. Recomendam também a adoção de novos referenciais de desempenho e atuação por meio da inserção da variável socioambiental nas atividades diárias. Apesar de existir pesquisas que comprovam uma predisposição humana a cooperar, os autores mencionam alguns obstáculos para a adoção dessas mudanças, como recursos públicos limitados, estrutura fortemente hierarquizada da área pública e uma cultura organizacional contrária, muitas vezes reforçada pela resistência das administrações centrais.

Um avanço apontado é a Política Nacional de Resíduos Sólidos (Lei no 12.305/2010), que tem como objetivo a redução e não geração de resíduos. Isso se relaciona ao consumo responsável e pressupõe medidas administrativas de substituição no uso de materiais e adoção de novas rotinas (processos e tramitações virtuais, por exemplo). $\mathrm{O}$ aspecto social dessa lei é percebido, por exemplo, na obrigação do Poder Público de encaminhar material reciclável às cooperativas e associações de catadores, determinado pelo Decreto $n^{\circ}$ 5.940/2006.

Por outro lado, o livro alerta que a legislação precisa avançar, com a adoção de iniciativas governamentais relacionadas à concessão de áreas para instalação das cooperativas. Por trás desse apoio, é fundamental orientação jurídica para aprovação de projetos de financiamento, possibilitando a compra de equipamentos e o apoio técnico que profissionalizem a atividade de reciclagem de lixo. Dessa forma, seu exercício se dará com condições mínimas de salubridade e segurança.

No que tange ao controle da gestão pública, o livro apresenta o papel do Tribunal de Contas da União (TCU) em suas auditorias ambientais, que relatam a atuação dos gestores públicos, a partir da análise de suas ações sob a ótica do uso eficiente dos insumos e recursos naturais, tais como água e energia. Abordam ainda a aderência desses órgãos às leis e normas ambientais aplicáveis, como a Lei $n^{\circ} 10.295 / 2001$, que descreve a Política Nacional de Conservação e Uso Racional de Energia, e a Instrução Normativa SLTI/MPOG $n^{\circ}$ $1 / 2010$, que dispõe sobre os critérios de sustentabilidade ambiental na aquisição de bens, contratação de serviços ou obras pela administração pública, detalhada mais adiante.

Quanto ao uso racional de recursos, os autores alertam sobre a importância dos aspectos econômicos e administrativos na administração pública, que deve zelar de forma exemplar pelos recursos que utiliza. Mostram ainda a importância do exercício da liderança do governo federal, por ser grande consumidor de insumos, serviços e obras. Por causa disso, têm papel estratégico na revisão dos padrões de produção e de consumo, apoiados no tripé da atividade econômica, do meio ambiente e do bem-estar da sociedade.

Tal racionalização é evidenciada pelos autores, por exemplo, na rotulagem ambiental de produtos e construções, visto que aumenta a consciência dos consumidores e produtores para a necessidade de usar os recursos naturais de forma mais responsável. Ao mesmo tempo, a rotulagem busca criar segmentos de mercado para produtos de menor impacto ambiental, estimulando o desenvolvimento de tecnologias consideradas mais limpas.

Os autores argumentam também que a rotulagem ambiental pode ser utilizada nas contratações públicas como critério de sustentabilidade das licitações, auxiliando o governo na visibilidade e legitimidade de seus atos. Em razão do substancial impacto que o setor da construção civil exerce sobre as emissões de gases do efeito estufa, pela energia embutida na fabricação dos componentes construtivos, o livro analisa a importância do consumo energético resultante da iluminação e do condicionamento de ar, bem como da redução no consumo de água.

Sustenta ainda que os cenários normativos existentes são baseados em medidas voltadas somente para a aprovação formal dos projetos. Isso é apontado como um aspecto negativo, pois os regulamentos se resumem a requerimentos estritos com aplicação mecânica, configurando um distanciamento da realidade das atividades de construção.

No campo das leis, da normatização e das licitações sustentáveis, hoje se estima em torno de $16 \%$ do Produto Interno Bruto (PIB) brasileiro os gastos com as compras públicas. Isso deixa nítida, portanto, a força do poder de compra do Estado, no sentido de 
ter uma capacidade de orientar o mercado em direção a determinados bens ou serviços. Uma das bases legais para ancorar esse estímulo está na Lei n ${ }^{\circ}$ 12.187/2009, que define que produtos ambientalmente corretos são aqueles que, por exemplo, propiciam maior economia de energia e água e a redução das emissões de gases de efeito estufa e de resíduos.

Outro regulamento importante na visão dos autores é a Instrução Normativa $n^{\circ} 1 / 2010$, da Secretaria de Logística e Tecnologia da Informação do Ministério do Planejamento, Orçamento e Gestão (SLTI/MPOG). Caso estejam disponíveis no mercado, a preços razoáveis, produtos que sejam, por exemplo, fabricados a partir de material reciclado, recomenda-se que sua compra deve ser priorizada. A mesma norma indica que os projetos de engenharia busquem economia na operacionalização e na manutenção das edificações, tanto em reformas quanto em obras novas.

Dentro do escopo de programas e educação ambiental, participantes dessa coletânea afirmam que existe uma disfuncionalidade no serviço público, com servidores executando atividades que ficam aquém de seu conhecimento e capacidade, em contextos de assédio moral, baixa autoestima, excesso de trabalho e de responsabilidades, falta de acesso a programas de capacitação e escassez de recursos financeiros.

Com o objetivo de alcançar maior capilaridade e valorização de iniciativas pontuais, os órgãos públicos dão mais autonomia a setores e instituições capacitadas. Dessa forma é incentivado o protagonismo dos participantes, que se tornam multiplicadores das ações em suas respectivas localidades.

A atividade de avaliação da conformidade também é citada no livro, tendo em vista o comércio globalizado, competitividade das empresas, segurança e saúde do consumidor e preservação do meio ambiente. Destacam-se dois programas de avaliação da conformidade desenvolvidos pelo Instituto Nacional de Metrologia, Qualidade e Tecnologia (INMETRO), que incorporam o enfoque sustentável: o Programa Brasileiro de Certificação Florestal (CERFLOR) e o Programa Brasileiro de Certificação em Responsabilidade Social (PBCRS), que contemplam conceitos considerados pelos autores como os mais avançados na área de sistemas de gestão de responsabilidade social, assunto principal da norma NBR 16001:2004.

No que diz respeito à $\mathrm{A} 3 \mathrm{P}$, registra-se que sua criação se deu em 1999, por iniciativas voluntárias dos servidores do Ministério do Meio Ambiente (MMA). Em reconhecimento da mudança de paradigma que esse movimento representou, a A3P recebeu um prêmio pela UNESCO, em 2002, em razão da relevância da iniciativa e dos resultados positivos. Ela tem sido incluída continuamente no plano plurianual do governo federal, tornando-a um referencial de sustentabilidade nas atividades públicas.

A A3P foi estruturada em cinco eixos temáticos prioritários: uso racional dos recursos naturais e bens públicos; gestão adequada dos resíduos gerados; qualidade de vida no ambiente de trabalho; sensibilização e capacitação dos servidores; e licitações sustentáveis. Para introduzir uma agenda ambiental em cada órgão, recomenda-se a elaboração de um diagnóstico, que deve conter informações sobre aspectos de todos os eixos temáticos, bem como elaborar um Programa de Gestão Socioambiental, que deve estabelecer objetivos específicos para cada eixo, ações a estabelecer e metas mensuráveis.

É fundamental para a efetividade da A3P a mobilização e sensibilização dos usuários, assim como o planejamento e monitoramento das ações, com o uso de indicadores de desempenho. Atividades simples e práticas nos órgãos são exemplificadas e estimuladas, como a coleta de pilhas usadas, a reciclagem de papel e óleo de cozinha, o uso de canecas e copos de vidro (em substituição a copos descartáveis) e a redução do número de lâmpadas fluorescentes nas luminárias.

Os autores ponderam que o programa A3P tem um especial efeito multiplicador e transformador, pois se baseia na educação ambiental, na mudança de cultura e de hábitos por parte dos servidores públicos. Tal mudança pode ser levada para o restante da sociedade, às suas residências, bairros e cidades, melhorando a imagem da administração pública, indo de encontro à visão estereotipada e presente da corrupção e do estigma de excesso de gasto nos órgãos públicos.

Percebe-se, portanto, que os organizadores da presente obra procuram focar as ações da gestão 
pública em uma abordagem simultaneamente econômica, social e ambiental, coerente com o tripé da sustentabilidade. $\mathrm{O}$ texto sustenta a necessidade de avanços, como na formatação de nossa legislação, de forma a ampliar o leque de instrumentos de que o Poder Público dispõe para racionalizar seus serviços, preservando a natureza, mantendo a qualidade e cumprindo seu papel constitucional.

Esse avanço vem ocorrendo, por exemplo, na edição da Instrução Normativa do SLTI/MPOG $n^{\circ}$ 2/2014, na qual é exigido dos novos prédios públicos federais um desempenho energético superior. Nesse caso, o selo de eficiência da Eletrobrás, chamado "Procel Edifica", deverá se enquadrar na categoria " $A$ " em todas suas vertentes: envoltória, iluminação e condicionamento de ar.

Pela análise da obra, também fica nítido que o fator humano dentro da gestão sustentável é valorizado nesse livro, pois sem a motivação e conscientização dos agentes públicos não é possível a introdução de medidas inovadoras e que tragam resultados concretos às instituições.

Não obstante esse destaque, a obra não inova no aspecto econômico da sustentabilidade na administração pública, especialmente em ações em que há maior visibilidade na sociedade, como as compras e construções sustentáveis. Tal ênfase é justificada tanto pela premissa legal do Estado, vinculada à Lei n ${ }^{\circ}$ 8.666/93, quanto pelo aspecto político-institucional, posto que auxilia os gestores públicos em suas decisões.

O conjunto do livro serve como apoio a pesquisadores no campo da administração pública que buscam exemplos práticos de ações efetivas de gestão socioambiental. Tais ações, ancoradas em uma legislação abrangente como a brasileira, podem igualmente servir de estímulo a outros gestores interessados em voltar a atenção de seu corpo funcional aos benefícios que uma postura de defesa do meio ambiente provoca na sociedade.

A atual exigência da elaboração de programas de logística sustentável nos órgãos, por exemplo, conforme descreve o Decreto Federal $n^{\circ} 7.746 / 2012$, veio a corroborar para que haja interesse de gestores sobre o tema. Por consequência, pode despertar a busca de literatura como a aqui estudada, quebrando paradigmas e promovendo a disseminação de conhecimentos entre os entes da administração pública, em todas as esferas.

A engrenagem da administração pública funcionará, de acordo com os autores, com a redução do consumo de recursos naturais, a destinação adequada dos resíduos gerados e o rompimento com parâmetros incompatíveis com a capacidade de existência humana no planeta. A relação entre sociedade e meio ambiente deve, portanto, ser construída com o intuito de passar para a geração seguinte condições iguais ou melhores do que aquelas que herdamos. 